\title{
Stories of Life Transition: Subjective Well-Being and Ego Development in Parents of Children with Down Syndrome
}

\author{
Laura A. King, Christie K. Scollon, Christine Ramsey, \\ and Teresa Williams
}

Southern Methodist University

\begin{abstract}
Eighty-seven parents of children with Down Syndrome (DS; 63 women, 24 men) wrote narratives about finding out that their child had DS and completed questionnaire measures of subjective well-being (SWB) and stress-related growth and completed the Sentence Completion Test as a measure of ego development. Forty-two of these individuals participated in a follow-up 2 years later. Foreshadowing and happy endings in the stories were related to heightened SWB at both time periods. Evidence of accommodative change - actively experiencing a paradigmatic shiftwas related to stress-related growth and ego development at both time periods. A high sense of closure and accommodation in the stories was associated with the highest levels of stress-related growth. Implications for research on well-being and personal growth are discussed. (c) 2000 Academic Press
\end{abstract}

The first 24 hours we were led to believe that our daughter was so bad off that we actually prayed to God to take her from us now versus later.

A wave of feelings passed through me-shock, fear and tremendous sadness and protectiveness toward my son.

I remember feeling a little jealous of the mother in the bed next to menursing her new "whole" child.

I remember feeling as if I was being punished.

Major life changes, by definition, require individuals to come to terms with a new set of life circumstances. Some life changes, such as the ones

We thank Greg Ligon for his assistance in participant recruitment and data collection. We also thank Courtney Bell, Camille Patterson, Sonia Sethi, Jo Meier, Jeff White, Tom Kennedy, Tom Scollon, Greg Ligon, Erik Day, and Linda Fisk for their assistance in content analysis and coding. Finally, we thank the parents who participated in the study, without their generous cooperation and candor the project could not have been completed. This research was supported by NIMH Grant 54142. Portions of this research were presented at the Nags Head Conference on Personality and Social Behavior, June, 1998, West Palm Beach, Florida Correspondence and reprint requests should be addressed to Laura A. King at Psychology Department, Southern Methodist University, Dallas, Texas 75275-0442. Electronic mail may be sent to lking@mail.smu.edu. 
described in the quotes above, involve irrevocable alterations in our lives, requiring us to redefine the very meaning of our existence, to seek out new sources of purpose, and to reassess our priorities. These quotes were taken from participants in the current study, all of whom were describing the experience of finding out that they would be parenting a child with Down Syndrome (DS). It is not difficult to conclude that such a life change can be experienced as catastrophic. Yet, Van Riper, Ryff, and Pridham (1992) found that such parents did not differ from parents of children without DS in their level of individual, marital, or family functioning. Apparently, in the face of an experience that might be viewed as catastrophic, people are able to live satisfying lives.

One of the ways that people make sense of potentially devastating experiences is by telling the story of the experience (cf. Pennebaker, 1989). Human beings are storytellers. We use stories to make sense of experience, to bring order to perceptions, and to attach ourselves to various sources of meaning. The purpose of the present study was to examine how aspects of the stories that parents of children with DS tell about their life transition relate to the parents' subjective well-being (SWB), personal growth, and personality development. We used stories of life transition as a means of examining the ways that individuals had come to encapsulate their experience, examining the coherence of the story and the degree to which that story contained evidence of a hard-won battle to make meaning of life circumstances. We were interested in the stories parents would tell about finding out that they would be parenting a child with DS - assuming that that story had been retold many times and that it might represent a distillation of the experience for the person (McAdams, 1996). These transition stories were assumed to be organizing structures in which might be manifested such psychological processes as positive reframing, the reassertion of the predictability and comprehensibility of the world, and accommodation (Block, 1982). Specifically, this study examined whether telling stories that possess features that have been associated with adaptive functioning - e.g., having a happy ending-would relate to heightened SWB. In addition, these transition stories were used to gain a measure of accommodative change (cf. Block, 1982) so that we could examine how consciously struggling with a major life transition may relate to heightened personal growth and personality development. Before describing the specific aspects of this study, we review various lines of research that bear on the predictions we made with regard to story characteristics that might relate to enhanced levels of SWB and then we consider how a story might reveal the process of personality development.

\section{SUBJECTIVE WELL-BEING AND STORYTELLING}

Research from a variety of areas has converged on a fascinating conclusion: the stories we tell about our experience not only reveal aspects of our 
personal characteristics they also serve as a source of comfort and a medium of coping in the face of traumatic life events. The role of stories in coping has been demonstrated by a number of researchers. It is notable that the research we review here is not narrative research, per se. Rather these programs of research suggest what we might look for, in assessing whether a story is coherent.

Literature on coping with adversity has emphasized the adaptive value of positively reinterpreting negative life events (e.g., Taylor, 1983, 1989). Affleck and Tennen (1996) have identified the theme of finding benefits in traumatic life events in a wide range of theories of coping with trauma (e.g., Taylor, 1983; Janoff-Bulman, 1992). Tennen and colleagues have shown that finding benefits in a wide range of negative experiences (e.g., Tennen, Affleck \& Mendola, 1991a,b) is related, prospectively, to heightened psychological adjustment. Individuals who are able to focus on the positive aspects of negative life events adapt more effectively (Taylor, Wood, \& Lichtman, 1983; Thompson 1991). For example, an individual who has cancer may conclude that the experience has allowed her to reorganize her priorities, to focus on the truly important things in life, etc. Placing the research literature on benefit-finding in a narrative context, we might infer, then, that an effective story is one that has a happy ending. What is positive reappraisal if not constructing a positive end to a potentially negative life experience?

A second interesting aspect of the literature on coping with adversity is that this research has shown the importance of reasserting beliefs that the world is a predictable, safe place (e.g., Janoff-Bulman, 1992, 1998). Faced with a traumatic, life changing event, individuals may generate naïve theories about how and why the event occurred (Taylor \& Armor, 1996). These theories may include idiosyncratic connections that have no bearing in realityi.e., they may be fictions or illusions. For instance, if a woman with breast cancer traces her diagnosis to an injury to her breast, such a connection may not reflect reality but may serve as a personally significant aspect of the story of her disease. Krantz (1998) has pointed out the difficulty human beings (including scientists) have with the notion of chance and the randomness of occurrences. The need to make sense - to find meaning and coherence in life events - is arguably a central human need (cf. Frankl, 1985; Janoff-Bulman, 1992; Janoff-Bulman \& Berg, 1998). Confronted with a chance event, we search for signs of meaning. From a narrative perspective, we might say that storytellers transform random events into meaningful symbols. Such symbols may be taken as portents of negative events to come-what in literary terms would be called foreshadowing. Foreshadowing in a story refers to signs warning of forthcoming tragedy. Symbolically representing coming events is a way in which narrative coherence is enhanced. Thus, the bad dream about a tragedy becomes a portent of future disaster when the story of the disaster is told. 
The belief that one has been sent a warning or has otherwise experienced a preparatory event about coming catastrophe helps make sense out of what has happened and may provide for an enhanced sense that the world is a predictable place (cf. Janoff-Bulman, 1992, 1998; Janoff-Bulman \& McPherson-Frantz, 1997; Krantz, 1998). Such a belief may also enhance the experience of meaning in the event and the sense that the event was somehow foreseeable or even controllable (Thompson, 1991). Thus we might expect that a coherent story might include foreshadowing and sense that one might have seen the event coming.

\section{PERSONAL GROWTH, PERSONALITY DEVELOPMENT, AND STORYTELLING}

One way in which individuals construct a happy ending for the story of a life trauma is through the belief that they have grown through or been transformed by the experience (cf. Janoff-Bulman, 1992; Janoff-Bulman \& Berg, 1998; Taylor \& Armor, 1996). Is this sense of personal growth through traumatic life experiences a fiction or a reflection of real change? Stressrelated growth (SRG) refers to the subjective sense that one has grown as a person as a result of some important life event (Park, Cohen \& Murch, 1996). After some stressful life experience one might feel increased independence or that one has stopped taking things for granted. Though these sorts of subjective assessments might be termed illusions, Taylor and Armor (1996) acknowledged (albeit in a footnote) that the term "illusion" may be misleading here, since the sense of personal growth these individuals report may in fact be a reality. Park et al. (1996) found that life events were related to perceived growth and that perceived growth was reflected in other changes in individuals' personality characteristics.

Personality development has also been shown to occur in association with life experience (Bursik, 1991; Helson \& Roberts, 1994). Loevinger (e.g., 1976; Loevinger \& Wessler, 1970; Hy \& Loevinger, 1996) views ego development (ED) as a movement from impulsiveness and preoccupation with bodily feelings to impulse control to regulation and the capacity to experience and tolerate conflict. ED may be defined as the level of complexity with which the person is able to conceive of and experience himself or herself and the world. According to Loevinger's theory, at the earliest stages of ED, we experience ourselves and the world in very simple ways. As we mature psychologically, we come to experience ourselves and the world in more complex ways. It is notable that Loevinger's approach to development is qualitatively different from the notion of SRG via life experiences. The mature person is not assumed to be living happily every after-rather maturity may be accompanied by an ambivalence that a less mature person would be incapable of experiencing.

Loevinger (1976) noted that only when the environment fails to conform 
to the person's expectations is there potential for development (cf. Kegan, 1982). In support of this assertion, Helson and her colleagues (e.g., Helson, 1992; Helson \& Roberts, 1994; Helson \& Wink, 1987) have demonstrated that "difficult times" may be a catalyst for personality development. For example, women who had a higher degree of "life stimulation" (e.g., a woman pursuing a career in the late 1950s or early 1960s or experiencing disruption such as divorce or career failure) tended to show a greater degree of ED over 31 years. The mechanism that has often been assumed to be responsible for this ED through life experience is accommodation (Block, 1982). Block (1982) discussed Piaget's developmental processes of assimilation and accommodation as mechanisms of personality development. In assimilation, the individual avoids any essential change and manages to simply assimilate a new experience into his or her existing framework. When assimilation fails the person may "construct or invent new schemes that are equilibrating" (Block, 1982, p. 291). Accommodation may require that one rethink one's essential beliefs about the goodness of the world, the fairness of life, and one's special place in the universe. Janoff-Bulman and Berg (1998) elegantly describe this process as disillusionment in response to traumatic life events followed by the reinstatement of meaning. They emphasize the necessity of such challenging life events-and the ways that personal gains in response to negative events are inextricably tied to the events themselves.

In past research the process of accommodative change has typically been assumed to have occurred, essentially because people did, in fact, increase in ED. Accommodation as a process has not been measured. In the present study, we sought to measure the accommodation process in parents of children with DS, through narrative accounts of this life-changing experience. We assumed that if individuals had experienced an essential change in their orientations to the world, such a change would be reflected in their stories about the transition. For example, accommodation might be manifested in descriptions of the transition as particularly difficult, as challenging one's beliefs, as quite disruptive to one's life, and as requiring a change in one's world view. In addition, stories might reveal that the storyteller is looking back on a more naïve version of the self and may contain reference to the experience of being changed by the event.

We have argued that constructing coherent stories with happy endings tends to be associated with psychological well-being. At the same time, experiencing accommodative change seems to involve being truly challenged by life experience, not settling for easy answers, and having one's sources of meaning questioned. The contrast is quite stark between the certainty of a clear, orderly story vs. the relativism and uncertainty required for development. The unavoidable conclusion is that psychological well-being and personality development may not always coincide with ego development. Indeed, historically, ED has not been related to adjustment or well-being 
(Vaillant \& McCullough, 1987). It is, perhaps, worthwhile to emphasize once again that $\mathrm{SRG}$ - one's subjective sense that one has benefited from a stressful life event - and ED are quite different processes, though both refer to a kind of growth. It is arguable that feeling like one has grown is more akin to positive well-being, itself. ED, in contrast, refers to a process that might not be available to awareness and that might be associated with the experience of ambivalence and conflict.

\section{OVERVIEW AND PREDICTIONS}

Participants were parents of children with DS who completed two mailin surveys, 2 years apart. The first survey included measures of SWB, SRG, and ED and narratives about the circumstances involved in finding out that their child had DS. Two years later, participants were sent a follow-up packet containing measures of SWB, SRG, and ED. Two types of content analyses were performed on the transition stories. First, we examined whether the narratives featured characteristics of an effective story-what we will refer to as the "storiedness" of the narrative accounts (e.g., foreshadowing, happy endings, resolution or closure). We also coded for happy beginnings in order to examine whether it is the affective quality of the ending that is truly important. Next, we looked at the ways that individuals described the life change itself, focusing on the extent to which the life change was acknowledged to be truly disruptive, to require a paradigmatic shift for the person and, perhaps therefore, to be a transformational experience. Using this coding we developed a measure of accommodation.

Predictions were made with regard to SWB, SRG, and ED. Though the measures of SRG and ED were predicted to have parallel relations with content analytic categories, we did not expect these two measures to correlate, necessarily. In addition, ED was expected to be independent of SWB. Thus, the three criteria were treated as relatively independent measures of three distinct aspects of persons. First, we predicted that foreshadowing, happy endings, and degree of closure would relate to heightened SWB. Second, we predicted that accommodation would relate positively to SRG and ED. That is, the more the narrative indicated struggle, an openness to the negative aspects of the circumstances, and a "paradigmatic" shift, the more SRG and ED were expected. Finally, a more tentative prediction was made with regard to the interaction of accommodation and closure in predicting SWB, SRG, and ED. It was predicted that a combination of accommodation and closure would be related to the highest levels of SWB, SRG, and ED.

\section{METHOD}

\section{Participants and Procedures}

An invitation to participate in the study was mailed to individuals on a variety of mailing lists for DS support networks. In addition, potential partici- 
pants were recruited at informational meetings at various hospitals in the Dallas/Fort Worth area. Interested individuals returned a postcard and were mailed a packet containing questionnaires as well as narrative questions and return postage. The packets also included a brief true-false measure of the child's disabilities.

A total of 132 packets were mailed out and 87 were returned (66\%). The main reason given for those who did not complete the packet was time involved in completing the measures (approximately $2 \mathrm{~h}$ ). The initial sample consisted of 63 women and 24 men. Ages ranged from 26 to 67 with a mean of $42.23(S D=8.34)$. Most of the parents $(94.9 \%)$ were White/not Hispanic, with $1 \%$ each being African-American, Hispanic, Asian, and other. The modal income level was $\$ 50,000$ to $\$ 70,000$ (38\%), with $30 \%$ reporting more than that amount and $33.3 \%$ reporting less. The modal education level was a B.A. (38\%), and all but 5.6\% had attended at least some college. Most of the parents were currently married $(89.7 \%$, with $9 \%$ being divorced and $1.3 \%$ widowed). ${ }^{1}$ The average number of children was $2.88(S D=1.72)$ and the average age of the child with DS was 6.70 years $(S D=6.72)$. The modal age was 3 years old and the median was 4 . Most of the children $(90 \%)$ were under the age of 13 , though $4 \%$ were over 18 (with the oldest adult "child", being 38 years old). Though this age range is quite broad, all cases were included in analyses. ${ }^{2}$ The vast majority of children resided in the home $(92.3 \%)$. Only $7 \%$ of the participants found out their child had DS prenatally. The rest found out either immediately after birth $(39.4 \%)$ or days after $(50.7 \%)$. With regard to the severity of the child's disabilities, participants were asked to answer a set of true-false questions. For participants whose children were over the age of 3 years, $70 \%$ were able to go to the bathroom alone, $26 \%$ had difficulty understanding what was being said to them, $37 \%$ knew their own address, $96 \%$ were able to feed themselves, and $96 \%$ were able to walk without help. All participants were paid $\$ 20.00$ for completing the initial packet.

Two years after the initial packets were returned, a follow-up packet was sent out to the original participants. A total of 42 participants (33 women, 9 men) completed the follow-up packet and were paid $\$ 20.00$ in return. The mean age of the follow-up sample was 43.19 years $(S D=10.14)$ and the mean age of their child with DS was 7.89 years $(S D=6.32)$. Although considerable attrition occurred in the sample, the subset who completed the

${ }^{1}$ Six participants were married to each other (three couples). All analyses were conducted with and without the married couples included. Results were essentially identical and so all analyses include these participants.

${ }^{2}$ All analyses involving age of child were conducted with and without the adult children. In each case, results with the adult children excluded were either stronger or the same as those reported in this paper. 
follow-up did not differ at Time 1, from the other participants, on age, income, child's age, child's disability, and number of children (all $t$ values, $\leq 1.0$ ). Nor did these individuals differ significantly from those who did not complete the follow-up on any of the self-report well-being measures, the measure of ego development, or any of the content analytic variables measured (all $t$ 's $\leq 1.80$ ). Of those who did not complete the follow-up, 20 were no longer living at the same address, and 24 reported that the time involved was prohibitive. One participant's child had died in the 2 years. The instructions for the second packet read as follows, "Some of the questions might seem familiar to you. Answer the questions as they apply to your life now. Your responses can be the same or different from your past responses."

\section{Materials}

Questionnaire packets at Time 1 included a number of demographic questions as well as questions pertaining to the child with DS. In addition, participants completed a variety of well-being measures and narratives.

SWB measures. Participants completed measures of satisfaction with life, sense of coherence, and self-esteem. The Satisfaction with Life Scale (SWLS; Diener, Emmons, Larsen, \& Griffin, 1985) is a 5-item measure of general life satisfaction. Items are rated on a scale from 1 (strongly disagree) to 5 (strongly agree). A sample item is "If I could live my life over I would change almost nothing." The Sense of Coherence Scale (SOC; Antonovsky, 1988, 1993) contains 29 items that are rated on a scale from 1 (strongly disagree) to 5 (strongly agree). Sense of coherence entails a feeling of confidence that the world is predictable, explainable, and structured, as well as a feeling that challenges are within the person's ability to resolve. Sample items from the SOC are "There is always a solution to the painful things in life" and "How often when you think about your life do you feel how good it is to be alive?', The Life Orientation Test (LOT; Scheier \& Carver, $1985)$ is an 8-item instrument measuring dispositional optimism, the tendency for individuals to chronically expect favorable outcomes. Each item is rated on a five-point scale from disagree on the low end to agree on the high end. The LOT includes items such as "Every cloud has a silver lining", and 'I'm always optimistic about my future." The Rosenberg Self-Esteem Scale (Rosenberg, 1979) is a 10-item scale including items such as "I take a positive attitude toward myself' and "I think I am a good person, at least on an equal basis with others.' This scale measures a general positive feeling about the self and items are rated on a 1 to 5 scale.

Stress-related growth. Participants also completed a questionnaire measure of stress-related growth. The Stress Related Growth Scale (SRGS; Park et al., 1996) is a 26-item scale measuring self-perceived positive outcomes resulting from a stressful life experience. Items are rated on a three-point scale with higher scores indicating more perceived growth. Sample items 
TABLE 1

Means and Standard Deviations for SWB, StressRelated Growth Measures

\begin{tabular}{lrl}
\hline & Mean & $S D$ \\
\hline Time 1 $(N=87)$ & & \\
$\quad$ Life satisfaction & 3.88 & .18 \\
Sense of coherence & 3.35 & .26 \\
Optimism & 4.04 & .64 \\
Self-esteem & 4.40 & .53 \\
Stress-related growth & 2.30 & .43 \\
Time 2 $N=42)$ & & \\
Life satisfaction & 3.98 & .80 \\
Sense of coherence & 3.58 & .47 \\
Optimism & .97 & .62 \\
Self-esteem & 4.37 & .45 \\
Stress-related growth & 2.25 & .34 \\
\hline
\end{tabular}

Note. For SWLS, SOC, LOT, and Rosenberg SelfEsteem scale, items were rated on a scale from 1 (strongly disagree) to 5 (strongly agree). For SRGS, items were rated from 1 (not at all) to 3 (a great deal).

include "I feel freer to make my own decisions" and "I learned that it's okay to ask others for help." The instructions were revised to indicate that participants should respond to questions as they pertain to the experience of parenting a child with DS. Means and standard deviations for all self-report measures are shown in Table 1.

Ego development. To measure ego development, participants completed the 18-item version of the Sentence Completion Test measure of ED (SCT; Loevinger \& Wessler, 1970; Hy \& Loevinger 1996). In this measure, participants are given 18 stems and space to complete the statements. Sample statements include "Women are lucky because ..." and "Raising a family ..." Participant responses were scored according to the most recent guidelines (Hy \& Loevinger, 1996). When scored according to guidelines, the SCT has shown good test-retest, interrater, and internal consistency reliability (e.g., Loevinger \& Wessler, 1970). In addition, longitudinal studies support the notion that this test measures sequential stages of personality development (e.g., Redmore \& Loevinger, 1979). Additional studies have shown that this measure of personality development can track development in response to life events (Bursik, 1991). Once the responses are coded each individual is given a total protocol score (TPR). These scores correspond to the eight ego levels described by Loevinger \& Wessler (1970): Level 2, Impulsive (egocentric and dependent); Level 3, Self Protective (opportunistic); Level 4, Conformist (respect for rules); Level 5, Self Aware (allowing exceptions 
to the rules); Level 6, Conscientious (self evaluative, occupied with achievement); Level 7, Individualistic (tolerant of differences); Level 8, Autonomous (coping with conflict); Level 9, Integrated (concerned with identity and mutuality).

The SCT responses for both time periods were transcribed so that all responses to a given item were listed together for the entire sample. Scoring was performed using the guide developed by Hy and Loevinger (1996). A set of six raters had been trained in the scoring system and had achieved at least a $96 \%$ agreement with the expert scoring on practice materials for the items they scored. All raters were blind to the narrative accounts of the participants. Pairs of raters coded 6 items each. The percentage agreements for the 18 items ranged from a low of $66 \%$ to a high of $98 \%$. Eleven of the eighteen items had agreement over $80 \%$. The average number of agreements was $88 \%$. All disagreements were resolved by discussion. The item ratings were then regrouped according to participant, and total protocol ratings (TPR) were assigned using the automatic ogive rules discussed by Hy and Loevinger (1996). Using these rules, each participant was a given TPR score. Individuals who completed the follow-up survey were given two scoresone for each time period. The TPR scores at Time 1 and Time 2 both ranged from 4 (Conformist) to 8 (Autonomous). The modal ego level was 6 (Conscientious), at both time periods, which is somewhat high relative to college samples typically used. Sum scores were also calculated for each time period. At Time $1(N=87)$, sums ranged from 78 to 130 with a mean of 94.43 (SD $=8.12)$. At Time $2(n=42)$, sums ranged from 78 to 111 , with a mean of $95.51(S D=7.37)$. For the subsample who completed both the Time 1 and Time 2 measures, $44 \%$ stayed the same, 27\% increased, and 12\% dropped one level. Though ED is considered to be stable in adulthood, many studies have reported similar or higher regression rates (Adams \& Shea, 1979, reported 21\%; White, 1985, reported 32\%).

Narrative accounts. The packet included the following question: "Please write about the moment when you first were told that your child had DS. Be as detailed as possible. Write it like a story in the space below and on the back of this page if necessary.' 'Participants were given three-quarters of a page to write their narratives. The narratives ranged in length from 37 to 906 words $($ mean $=212.93, S D=166.44$, median $=165)$. Women wrote more than men (means $=237$ vs. $147, t(85)=2.27, p<.03$ ).

Content analysis of stories of life transition. The stories of how participants found out that they would be parenting a child with DS were content analyzed. First, three raters coded the stories for the presence of foreshadowing, happy beginning, and happy ending. "Happy beginnings"' was included only to control for the possibility that generally happy stories might be associated with SWB, rather than happy endings per se. Ratings were made in a $0-1$ format, with 1 indicating the story did have the characteristic. For 
foreshadowing and happy endings the judges showed strong agreement (mean interrater $r$ 's $=.91$ and .93 , respectively). For ratings of happy beginnings, the mean interrater $r$ was somewhat lower but still acceptable $(r=$ .70). The average of the three raters was used as the score for the dimensions. These three ratings were independent of each other (all $r$ 's $<.04$, n.s.). Twenty-five stories had some foreshadowing. Forty-three of the stories had a happy ending and 43 had a sad ending. Most of the stories (77) had unhappy beginnings.

The following are some illustrative examples of foreshadowing.

At our baby shower, we opened a box with a child care book. My husband opened it at random and started reading loud. I looked at him in horror as we both realized he was reading about DS.

I kept having feelings that something was wrong before I gave birth. All of the tests came back normal. In the last month, I had a dream and I sat up in bed and I grabbed my stomach and cried "Please don't let this child have DS." I believe that God was telling me and preparing me.

Deep in my heart I just knew that I was carrying a child with DS.

From the day I knew I was pregnant I think somewhere deep inside I knew our baby had DS.

\section{Examples of happy endings include the following.}

I know my daughter is quite special. It's as if she's part of another race or from another planet. She's definitely wired differently. And I think those wires are hooked directly to God. She's the closest I've come to an angel on Earth.

When I would go and hold my son the grief would go away, especially when he smiled. He would just seem to say: "Mommy, it's going to be okay.",

Examples of unhappy endings include the following.

Images of adults with DS flooded my mind. They were not pretty images. I was afraid he would die from the surgery and more afraid that he wouldn't.

Finding out was devastating. I was depressed, didn't want him. When I told my mother, she fainted. My other child became so upset due to the circumstances that she vomited. It was simply devastating.

We were given an Exceptional Parents magazine. On the way home from the blood test, I found a picture of a crib with a lid on it, like a cage. I remember wondering, what do we have? What are we faced with? I also remember thinking that now we'll never be normal.

Finally, accounts were content analyzed for the degree of closure and accommodative change they expressed. Because this study represents a first attempt to detect accommodation in stories, we included a variety of dimensions that we thought would relate to this kind of change. Recall, that accommodation refers to an essential change in the structures through which one experiences the world. Therefore, we included dimensions that would tap 
into the severity of the event, the degree of negative emotion experienced, the extent to which the person was an active participant in the story, and the degree to which the person struggled to make sense of the event. Two raters, blind to the participants' ego levels and questionnaire responses, independently rated the accounts. First, the raters scored each of the stories on six characteristics on scales from 1 (not at all) to 7 (extremely much). The dimensions included how active the participant was in the story (mean $=2.27$, $S D=.93$, interrater $r=.56$ ), how much the narrator experienced a major paradigmatic shift in his or her world view (mean $=2.30, S D=1.12$, interrater $r=.60$ ), how much the person explored and struggled with the experience $($ mean $=2.37, S D=1.29$, interrater $r=.75$ ), and how traumatic the experience was (mean $=4.70, S D=1.17$, interrater $r=.78$ ). In addition, narratives were coded for how much closure or resolution the person expressed $($ mean $=3.42, S D=1.96$, interrater $r=.77$ ), how much denial (vs. openly expressed negative emotion) the rater thought was present in the narrative (mean $=3.87, S D=1.37$, interrater $r=.46$ ), and how gradual vs. sudden the change was (mean $=5.62, S D=.84$, interrater $r=.48$; high scores indicated more sudden change).

Although many of the dimensions that were coded are quite abstract, the instructions to raters described each in detail. The reasonably high reliabilities indicate that the raters did have a shared sense of what was being scored. An example of the instructions to raters is the following description of "Paradigmatic Shift.',

Paradigmatic shift. This rating concerns the degree to which the change entails a paradigmatic shift for the person. There are two processes of development, assimilation and accommodation. Assimilation involves incorporating a new experience into one's existing structures. For our sample, this concept serves as a heuristic - it means that the person has managed to handle the change within his or her existing understanding of self and world. The second process, accommodation, means that the new experience requires a revision of structures - an essential change in response to the environment. For our sample, this concept serves as an analogy for qualitative change in how the person sees the world and him or herself. Accommodative change means that the person has been forced to change, centrally and qualitatively, his or her views of the self and world. ${ }^{3}$

To take into account the emotional tone of the stories, the raters also made two more ratings, on positive and negative emotion adjectives. Raters were presented with a list of emotion words and were asked to check those that were predominant in the narrative. Adjectives included happy, joyful, content, hopeful, and pleased and depressed/blue, frustrated, angry, worried/ anxious, hopeless, guilty, ashamed, and fearful. The positive and negative

${ }^{3}$ Full instructions for the content coding may be obtained at http://www.smu.edu/ $\sim$ psycholo/king.html. 
emotions were averaged within rater producing a positive affect (PA) and negative affect (NA) score. Scores could range from 0 to 1.0. The mean for NA was .26 $(S D=.19)$, with an interrater correlation of .78. For PA, the mean was $.11(S D=.15)$, with an interrater correlation of .96 .

Correlations among the content ratings are shown in Table 2. A principle components analysis was conducted to construct reliable scales. Two factors had eigenvalues greater than 1 , and examination of the scree plot indicated that two factors would best explain the data. Loading on the first factor were PA, closure, and denial (all positively), and trauma, NA, and sudden change (all negatively; eigenvalue $=3.02,34 \%$ of variance accounted for). Loading on the second factor were paradigmatic shift, exploration, and activity (eigenvalue $=2.25,25 \%$ of variance). Rotated factor loadings are shown in Table 2. Content dimensions were standardized and two composites were created-closure (the unit weight factor scores for the first factor) and accommodation (the unit weight factor scores for the second factor).

Excerpts from stories that scored high on the accommodation factor follow.

I remember this mental bargaining going on in my head. The problems in breast feeding shrank to nothing for me and I said to myself, "I can deal with this, just don't let the other things be true." When the heart defect was confirmed I said to myself, "I can deal with this, just don't let him have DS." The last thing I hoped for was mosaic Downs. That was the extent of my denial.

I was surprised how much I totally suppressed the information. Total denial for 3 weeks. . . . I was shocked at my own inability to deal with such an unexpected event. I cried a lot. The pain was so deep. I felt cheated-I could hardly function. I was so absorbed with my own fears. But I did regroup. I did grow. And I did learn to accept the situation. That opened the door for me to bond and love my child. But it took time.

I cried some and experienced waves of "Unknown" embracing me ... I knew little about DS - it was an abstraction. Any handicap fell into the category of a childhood memory of seeing "waterheads," as I was told or remember, out on a shopping trip getting into a bus. My daughter was flesh and blood and a good nurser and that was the reality I remember dealing with. I thought very little about her future but I knew I would bow to no predictions. Irrational thoughts came to me at times but did not consume much thinking time: "I must have DS too, it just hasn't been discovered yet." Or "This child must be a consequence for wrong decisions in the past."

Note that the accommodation stories are not necessarily more negative but rather involve a concerted effort by the person to deal with the situation. They also include a sense of being "blown away" by the experience. Finally, these types of stories tended to show some degree of self-objectification; that is, the person was likely to comment on his or her own coping processes.

Excerpts from stories scored high in closure include the following.

I was not familiar with DS, but I knew that she was given to me for a reason and that I would take care of her for as long as I was supposed to. . . . 
KING ET AL.

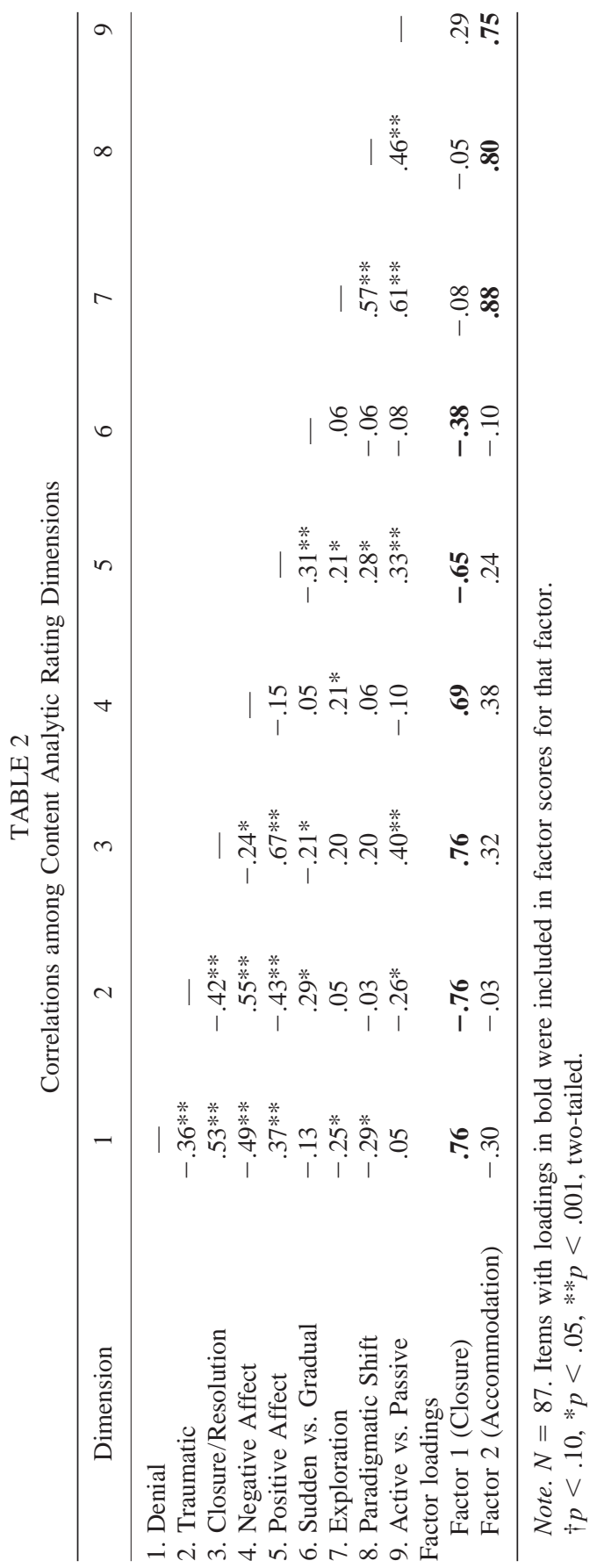


We knew that our daughter was going to get a very loving supportive family who would make sure she achieved everything possible for her.

I knew everything would be all right. He was first and foremost our baby boy and DS was one characteristic of Jamie. He is as much or more of a blessing to our family as any child could be.

As might be expected, stories high in closure were more likely to have happy endings $(r=.65)$. Accommodation and closure scores were unrelated $(r=.14$, n.s.). Because both scores were aggregates of standard scores, the means of the scales were 0 . Both distributions were unimodal. Accommodation was somewhat positively skewed (1.56) while closure was only slightly positively skewed (.39).

\section{RESULTS}

Before performing analyses to examine our main hypotheses, we examined the relations of the criterion variables and content analytic variables to sex and timing of diagnosis. No significant sex differences emerged on the SWB measures, SRG, or ED. In addition, no significant differences emerged on these variables with reference to the timing of diagnosis (prenatal vs. at birth vs. days after birth).

\section{$S W B, S R G$, and ED Measures}

Table 3 shows the correlations among all measures of SWB, SRG, ED, participant age, age of child with DS, and number of children in the family, within and across time periods. Several features of Table 3 are notable. With regard to SWB, not only did all measures correlate positively with each other within time periods, they also did so across the 2 -year period. Indeed, strong evidence for test-retest reliability is demonstrated for all of these measures (with correlations ranging from .52 for SOC to .77 for SWLS). Not unexpectedly, SRG and ED were not correlated with each other at either time period. Thus, a person's subjective sense that he or she has grown through a traumatic life event may or may not be reflected in the person's ED. There was some evidence of stability in scores for SRG and for ED. In addition, SRG was unrelated to concurrently measured SWB at both time periods. Interestingly, SRG at Time 1 was negatively correlated with SWB measures 2 years later. ED was positively correlated with self-esteem at Time 1. With regard to participant age, positive correlations were found for SOC, optimism, and self-esteem at both time periods. Participant age was also positively correlated with ED for those participants who completed the Time 2 measures. Although the age of the child with DS was largely unrelated to SWB, it was positively related to ED at Time 1 . The number of children in the family was a positive correlate of life satisfaction and SOC at both time periods.

Because of the strong relations between measures of the same constructs 


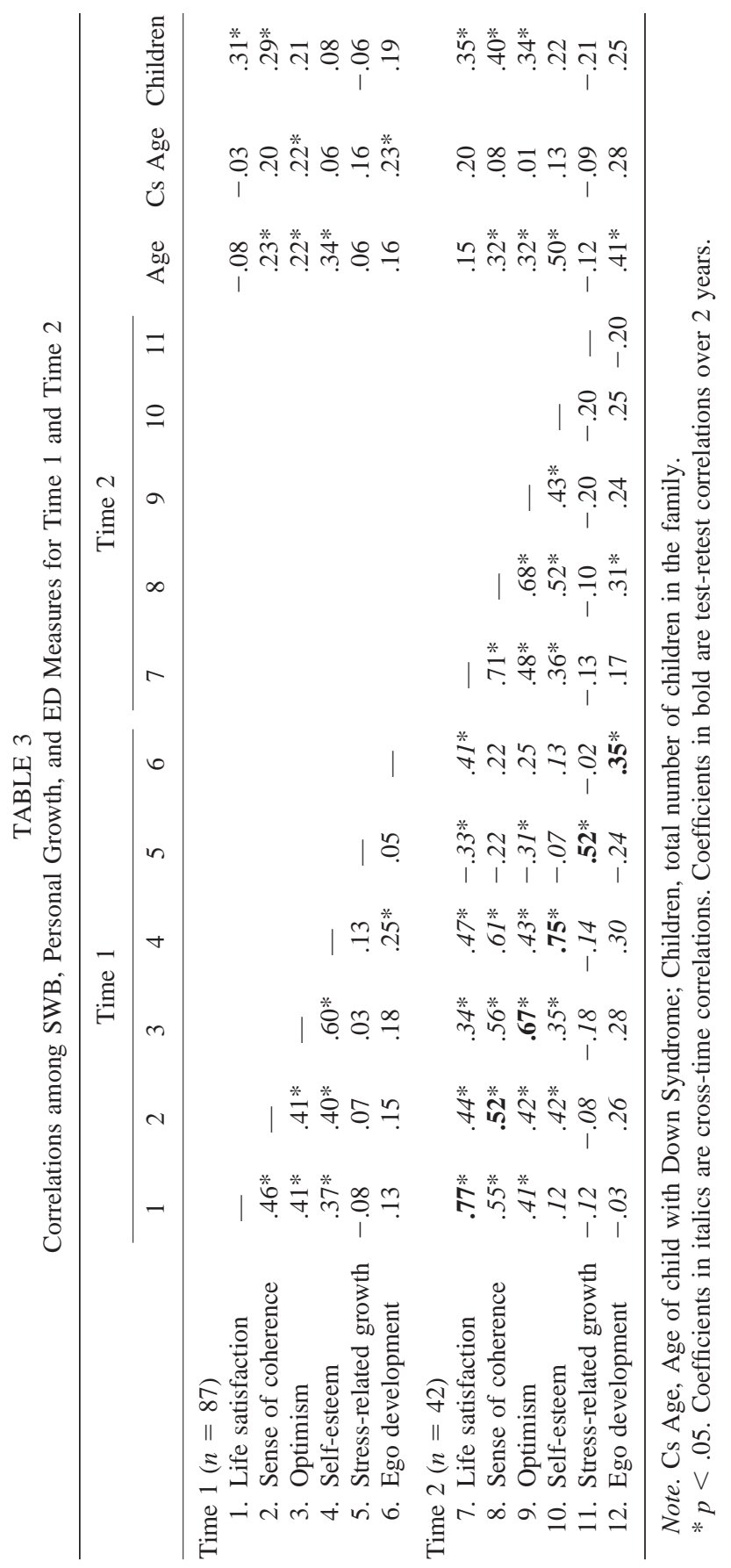


over the 2-year interval, most of the following analyses were conducted on each time period separately, rather than predicting Time 2 values, controlling for Time 1. Because the SWB measures were all significantly positively correlated, a composite SWB measure was created by averaging over the standard scores for the SWLS, LOT, SOC, and the Self-Esteem Scale within each time period. This SWB composite tapped feelings of satisfaction, optimism, and self-esteem but also a sense that life is meaningful and fulfilling.

Next, correlations were computed between the content dimensions, number of words in the narratives, sex, number of children in the family, and the age of the child with DS. There were no mean differences on any of the content variables between men and women. Age of the child and number of words in the narrative were positively correlated with accommodation ( $r$ 's $=.36$ and .34 , respectively, $p$ 's $<.05$ ). Thus, the longer the individual parented a child with DS, the more likely he or she was to experience accommodation. Foreshadowing was also related to the number of words in the narrative $(r=.31, p<.05)$. The only variable related to the number of children in the family was closure $(r=.25, p<.05)$-individuals with more children tended to experience closure.

\section{Story Coherence, Accommodation, and SWB}

To examine the main predictions of the present study, analyses were performed to investigate how the storied features of the narratives as well as their descriptions of change related to SWB, SRG, and ED. Correlations were computed between the content dimensions and the SWB composite, SRG, and ED. First, having a story with a happy beginning was not related to SWB, SRG, or ED at either time periods (all $r$ 's $< \pm .17$ at Time 1 and \pm .22 at Time 2).

Results with regard to the other four dimensions are shown in Table 4. As predicted, happy endings were related to heightened SWB at both time periods. Also, as predicted, the presence of foreshadowing as well as high closure in the narratives were related to heightened SWB, at both time periods. It is notable that happy endings and foreshadowing were not related to SRG or ED. Indeed, foreshadowing was significantly negatively related to SRG at Time 2. As predicted, accommodation was positively correlated with SRG and ED at Time 1 and was positively correlated with SRG at Time 2. Furthermore, the relationship of accommodation to ED obtained, even controlling for SRG. In a regression equation predicting ED from SRG and accommodation, SRG did not predict $\operatorname{ED}(\beta=-.036)$ while our content analytic measure remained related $(\beta=.24, p<.04)$. Thus, these initial results provide support for predictions with the notable exception of Time 2 ED-in which case none of the content dimensions was related to this variable.

Because the age of the child with DS and the number of children in the 
TABLE 4

Correlations among Narrative Characteristics, SWB, SRG, and ED, Controlling for Child's Age and Number of Children in Family

\begin{tabular}{|c|c|c|c|c|c|c|}
\hline & \multicolumn{3}{|c|}{ Time $1(N=87)$} & \multicolumn{3}{|c|}{ Time $2(N=42)$} \\
\hline & SWB & SRG & ED & SWB & SRG & ED \\
\hline \multicolumn{7}{|l|}{ Content (Time 1) } \\
\hline Happy Ending & $.31 * *$ & .05 & .06 & $.34^{*}$ & -.23 & -.14 \\
\hline Standardized $\beta$ & $.34 * *$ & .06 & .05 & $.34 *$ & -.14 & .16 \\
\hline Foreshadowing & $.23 *$ & .16 & .08 & $.47 * *$ & $-.41 * *$ & .00 \\
\hline Standardized $\beta$ & $.23 *$ & $.20 \dagger$ & .10 & $.37 * *$ & $-.38^{*}$ & .09 \\
\hline Closure & $.30 * *$ & .06 & .19 & $.37 * *$ & $-.26 \dagger$ & .13 \\
\hline Standardized $\beta$ & $.22 * *$ & .11 & .18 & $.34 *$ & -.25 & .06 \\
\hline Accommodation & .14 & $.28 *$ & $.23^{*}$ & .11 & $.40 * *$ & -.14 \\
\hline Standardized $\beta$ & .09 & $.23 *$ & $.23 *$ & .07 & $.33^{*}$ & -.05 \\
\hline
\end{tabular}

Note. SWB, subjective well-being composite; SRG, stress-related growth scale; ED, sentence completion test ego development measure; standardized $\beta$ 's, the betas for the content variable in regression equations controlling for the number of children in the family and the age of the child with Down Syndrome.

$\dagger p<.10, * p<.05, * * p<.001$, two-tailed.

families tended to relate to ED and SWB, regression equations were computed predicting SWB, SRG, and ED, entering the content dimension, age of the child with DS, and total number of children into the regression equation simultaneously. Standardized betas for the content dimensions are shown in Table 4. These regression weights indicate that the predicted relationships obtain even controlling for the number of children in the family and the length of time spent parenting the child. Partialling out the number of words in the narratives also had no impact on the correlations.

\section{Prediction of SWB, SRG, and ED Overtime}

Next, regression equations were computed regressing Time 2 values of SWB, SRG, and ED on Time 1 values of these variables as well as foreshadowing, closure, and accommodation, to attempt to examine the prospective prediction of SWB, SRG, and ED. Note that the shared variance between the two time periods limits the chances of any of the narrative variables predicting SWB, SRG, or ED at Time 2. With regard to SWB and ED, controlling for Time 1 values, none of the content dimensions contributed to the equations. However, for SRG, Time 1 levels contributed significantly to the equation $(\beta=.40, p<.01)$, but accommodation also contributed with marginal significance $(\beta=.25, p<.10)$, and foreshadowing contributed significantly and negatively $(\beta=-.29, p<.04)$. Thus, these results indicate that the accommodation process revealed in the transition stories does pre- 
dict, prospectively, self-reported personal growth. In addition, the use of foreshadowing tends to be negatively related to perceived personal growth.

\section{The Interaction of Closure and Accommodation}

Next, analyses examined how the interaction of closure and accommodation might predict SWB, SRG, and ED. It had been tentatively predicted that it might be most advantageous for the person to have a story that includes struggle but that, ultimately, has a closed, happy ending. Recall that happy endings tended to be strongly associated with a high degree of closure. To avoid multicollinearity in the analyses, a composite variable was created, averaging the standard score for happy ending with the other closure variables. Multivariate analyses were conducted looking at the impact of describing accommodative change and having a happy resolution in one's story on SWB, SRG, and ED. For these analyses, accommodation and closure scores were converted to mean deviation scores and the product of these two scores was used as the interaction term. Six hierarchical regression equations were computed, entering the main effects on the first step and the interaction term on the second step (Aiken \& West, 1993). For the three equations pertaining to Time 1 , results indicated that only main effects emerged-following the same pattern as the results in Table 4.

Turning to SRG at Time 2, a significant interaction did emerge. Results are shown in Table 5. The main effect for accommodation was qualified by a significant accommodation $\times$ closure interaction. The significant positive beta weight for the interaction suggests that individuals who were high on both or low on both accommodation and closure would report the highest levels of SRG. To further probe this interaction, simple regression lines were drawn, predicting SRG for participants low (one standard deviation below the mean), medium (at the mean), and high (one standard deviation above

\section{TABLE 5}

Hierarchical Regression Equation Predicting Stress-Related Growth at Time 2 from Accommodation and Closure

Unstandardized $\beta$

Standardized $\beta$

Step 1: Main Effects $R^{2}$ change $=.20^{*}$

Accommodation

$.48 *$

Closure

Step 2: Interaction Effects $R^{2}$ change $=.12 *$

Accommodation $\times$ Closure

Note. Multiple $R=.56, R^{2}=.31, F(3,38)=5.82, p<.01$.

$* p<.05$. 


\section{SRG by Accommodation and Closure}
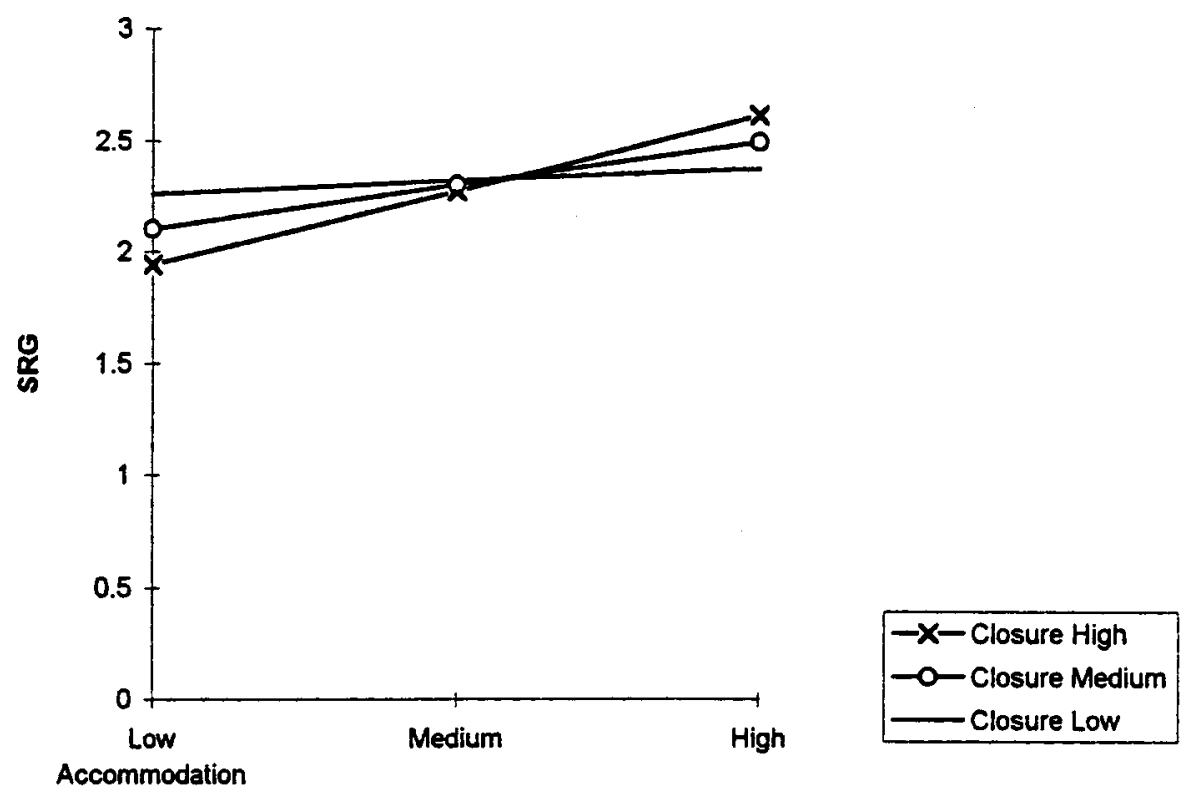

\section{Accommodation}

FIG. 1 Time 2 stress-related growth as a function of accommodation and closure in the transition stories. Lines are simple regression lines calculated from the hierarchical regression equation.

the mean) on accommodation and low, medium, and high on closure (Aiken \& West, 1993). Results are shown in Fig. 1.

As can be seen in Fig. 1, at high levels of accommodation, closure was positively related to SRG. However, at low levels of accommodation, closure was negatively associated with SRG. This pattern suggests two ways of reaching resolution - settling for an easy answer vs. struggling to a hard won conclusion. Individuals whose stories demonstrated accommodative change were more likely to report themselves as growing through the experience if they also told stories with resolved endings. It may be that some sense of closure is part of the naïve definition of growth through life experience.

\section{Supplemental Analyses}

Throughout the analyses thus far, very few significant relations emerged for Time 2 ED. Supplemental analyses sought to examine the predictors of ED at Time 2, given that participants in this study were relatively high in ego level at Time 1. First, ED scores were converted into a trichotomous 
TABLE 6

Hierarchical Regression Equation Predicting Ego Development at Time 2 from Time 1 Ego Level and Accommodation

Unstandardized $\beta$

Standardized $\beta$

Step 1: Main Effects $R^{2}$ change $=.13$, n.s.

Dummy Variable 1 (Levels 4 and 5)

Dummy Variable 2 (Level 6)

Accommodation

Step 2: Interaction Effects $R^{2}$ change $=.20 *$

Dummy $1 \times$ Accommodation

Dummy $2 \times$ Accommodation

Constant

\section{$-.26$}

.01

$-.56$

.89

$-.27$

2.17

Note. Multiple $R=.57, R^{2}=.33, F(5,33)=3.23, p<.02$.

$* p<.05$.

score in order to more evenly split the distribution. Levels 4 and 5 were collapsed into one level $(n=28)$, Level 6 was the second level $(n=39)$, and Levels 7 and 8 were collapsed into the third level $(n=20)$. Two dummy variables were created to represent these three levels of Time $1 \mathrm{ED}$, with the first dummy variable representing the lowest level and the second dummy variable representing the middle level. Next, the product of these dummy variables and the mean deviation accommodation score were computed. A hierarchical regression equation was computed predicting Time 2 ED from the dummy variables, accommodation (entered on the first step), and the product of these variables (entered on the second step). Results are shown in Table 6. The first step did not contribute to the equation significantly but a significant interaction did emerge on the second step. The significant interaction between the dummy variable for lower levels of ED and accommodation indicated that, at lower levels of Time $1 \mathrm{ED}$, accommodation was particularly positively related to Time 2 ED. Thus, accommodation was related to Time $2 \mathrm{ED}$, but only for participants who had room to grow over the 2 years. These results strengthen the argument that accommodation processes are related to ED-particularly for those who are at the conformist or self-aware levels of development. Individuals at those levels who demonstrated accommodative processes in their stories tended to grow over the subsequent 2 years.

Results indicate that SWB is related to one set of story characteristics (foreshadowing, happy ending, closure) while ED is related to another (accommodation). As a final test of these conclusions, we computed regression equations predicting SWB and ED from the content dimensions, controlling for the other criterion variable. As expected, SWB was significantly predicted by closure $(\beta=.26, p<.02)$, was marginally predicted by foreshadowing $(\beta=.18, p<.09)$, and was unrelated to accommodation $(\beta=.07)$ and 
$\mathrm{ED}(\beta=.16, p>.10)$. ED was significantly predicted by accommodation $(\beta$ $=.23, p<.05)$ and was unrelated to closure $(\beta=.03, p<.02)$, foreshadowing $(\beta=-.04, p<.02)$, or SWB $(\beta=.16)$.

\section{DISCUSSION}

Results of the present study strongly support two conclusions. First, having a coherent story (i.e., one featuring foreshadowing and a happy ending) tends to be related to heightened SWB. Second, telling a story that conveys one's struggle with a life problem - in which the person portrays him or herself as seriously challenged by life and struggling to make sense of it all-is associated with the subjective sense that one has grown, as well as with enhanced ED. A strong sense of closure in one's story is related to heightened SWB but may be negatively related to SRG. These results lend strong support to the notion that the stories we tell about our life experiences may illuminate two pathways - one to satisfaction and one to maturity. Importantly, regression equations predicting SWB and ED from each other and the content dimensions indicate that these pathways are independent.

A number of the results of this study warrant further discussion. For instance, it is interesting to consider why SWB at Time 1 was associated with lower levels of SRG at Time 2. One possible explanation for this finding may be that some amount of discontent is required for personal growth. If an individual feels happy and satisfied then he or she may be less likely to work toward resolution, struggle with difficult times, and have a sense of growing through that experience. The possibility that some negative feelings are required for personal growth is certainly suggested by a variety of perspectives (e.g., Loevinger, 1975; Janoff-Bulman \& Berger, 1998).

Though a sense of closure coupled with accommodation was associated with SRG, accommodation was not related to measures of SWB. In fact, accommodating the experience of parenting a child with DS was negatively related to SWB at Time 2, controlling for SWB at Time 1. This result suggests that personal growth may require a sacrifice of happiness. A number of authors have discussed the various components that can make up a good life (Becker, 1992; Myers \& Diener, 1995; King \& Napa, 1998; Ryff \& Singer, 1998). Our data demonstrate that two aspects of the good life, positive feelings and maturity, may not always coincide. Indeed, insight may come at the expense of feeling good. Conversely, it may be that rushing to a happy ending interferes with the process of development.

Because the data are correlational, the direction of causality is, of course, unknown. It may well be that individuals who are satisfied with their lives and experiencing high meaning in life write better stories than those who are unhappy. Still, it is interesting that happiness was associated with happy endings and foreshadowing but not happy beginnings, suggesting that, at the very least the SWB results are not due to an overall positivity. Indeed the 
results with regard to foreshadowing highlight the problem in calling these stories positive illusions. Believing that one has been "sent a sign" of a forthcoming life event is not necessarily a positive feeling or experience. Rather, the sense that one had some warning of impending events may simply relate to a heightened sense of meaningfulness or predictability.

An interesting area for future research might be to examine the degree to which the accommodation process is related to individual differences. It may be that established personality characteristics like need for cognition or openness to experience would predict the tendency to be open to the challenges of negative life events and to process these events in such a way as to develop the self. The role of defensive processes as potential interference in accommodation would also be an interesting issue to explore.

Some aspects of this project set it apart from previous work in this area. One of the problems in some of the previous research on life events and stress-related growth is that typically each participant is writing about a different life trauma-some about the loss of a loved one, the loss of a pet, a personal failure, or some kind of abuse. This type of procedure confounds the manageability of a trauma with the person's attempts to make sense of it. To avoid this problem we studied a group of individuals who share a similar life circumstance-parenting a child with DS. In this study we know that the events that the participants wrote about shared at least some central features. In addition, parenting a child with DS is an enormous life event but it is one in which adjustment and thriving is possible. It will be important to investigate whether these findings generalize to other samples of people who have undergone challenging life experiences.

Our discussion of ED resonates, to some extent, with the work on wisdom of Baltes and his colleagues. Baltes and Staudinger (1993) defined wisdom as expert knowledge — "the fundamental pragmatics of life permitting exceptional insight, judgment, and advice involving complex and uncertain matters of the human condition', (p. 76). Wise thinking is characterized by relativism, uncertainty, and contextualism. Importantly, wisdom is enhanced by life experiences that involve dealing with difficult and unstructured matters of life, or "wisdom facilitative experiences" (Baltes, Staudinger, Maercker, \& Smith, 1995). Again, this perspective indicates that life experience can propel personality development-but this experience involves confronting difficult and ambiguous life circumstances. We might argue that parenting may be a wisdom facilitative experience.

It is important to note that the paths to SWB and maturity are not negatively related but, rather, are independent. It is possible to be "sadder but wiser.' But it is also possible to remain engaged in reality, open to the complexity and uncertainty of human life while enjoying a sense of happiness and contentment. To examine the types of stories that were told by happy mature individuals, we performed median splits on the Time 2 SWB 
measure as well as the sum scores for Time 2 ED. Then, we examined stories told by participants who were above the median on both measures. There were 12 participants who fit this profile. Representative excerpts from their stories follow.

It was long enough ago that the word was Mongoloid. I was alone and it was late at night when the doctor told me. Of course my mind clicked in to an offensive mode of denial—bad dream — etc. I chose not to call my husband. . . . Instead-I laugh at this now because I was 33-I called my parents. I think I wanted them to fix things. They were pretty good at it in the past. . . . Then I realized that I was mourning as if my child had died yet I still had a nice fat baby in the nursery. I rang for him to be brought to me expecting him to be a monster instead of the cute thing I saw in the delivery room. I tore all of his clothes off of him and just looked at him. He was beautiful. There must have been some mistake. I held him and kept him with me until my husband came the next morning.

My heart felt as though it would break ... We did not know if she would live.... Should she live or die, what did life have in store for her? Could our family face this sadness? Were her parents up to it?

The doctor recommended immediately institutionalizing him and said it would be best if I never saw my son . . . it took a day of being a totally hysterical mother before they would let me see or hold my son. The moment I held him, I knew he would stay with me. He looked perfect to me, beautiful, full of love, only wanting love in return ... I soon learned that my son was not all that different from everyone else. ...

... I felt as though the earth had opened up and swallowed me. My world seemed to grow (almost tangibly) darker. In that short instant, my normal "perfect" life disappeared. I thought I would never be happy again. I would never laugh, never have fun. There was construction going on at the hospital and there was scaffolding outside my window. I wanted to crawl out on it and keep on going-just escape.

Several recurrent themes are notable in these stories. First, there is a sense of self-deprecation. In the stories told by the happy, mature parents, there is a strong sense of looking back, perhaps good-humoredly, on a more naïve, perhaps even silly, version of oneself. These stories include an acknowledgment of the person's own vulnerability and an openness to negative emotions. Another common characteristic is the particularly vivid ways in which experience is expressed. Finally, these individuals tend to mention the child's physical appearance as a source of enormous comfort. Interestingly, comparing these stories to the stories of mature unhappy individuals, we find that the only difference is in positive emotion and happy endings. Comparing the two groups, statistically, the only significant difference is the main effect for high SWB on closure and happy endings. An example from the sad mature parents demonstrates this difference:

I was 38 when I got pregnant. I knew the risks of Down Syndrome at my age but foolishly had the feeling nothing really bad could ever happen to me. Exactly a year 
before Genny was born we had some very close friends have a baby girl with Downs. We knew the physical characteristics, etc., from knowing them and seeing their baby. ... I chose not to have any prenatal testing done. As soon as she was born we knew she had Down Syndrome.

This story demonstrates the same self-deprecating tone as the previous stories, but it lacks the level of positive emotion expressed in the stories told by happy individuals.

A potential problem with the present study that deserves some consideration has to do with the particular characteristics of our sample. Nearly $90 \%$ of our sample came from intact marriages, which is certainly not representative of the general population or of parents of children with disabilities. Our participants were also well educated and tended to be drawn from an upper middle class background. These "privileged" characteristics of our sample exacerbate concerns over generalizability. However, as a first examination of accommodation processes in transition stories, our results may be all the more intriguing given the lack of variance that might be expected in such a homogeneous group. In addition, as much of the research on ED has involved individuals from a college setting, it is certainly worthwhile to have this opportunity to examine highly developed individuals who have experienced a truly life changing event.

While we acknowledge that the present results may not generalize to other samples, we'd also suggest that they may not be specific to the experience of parenting a child with DS. Indeed, one parent remarked upon returning her first packet that she would have enjoyed doing the same activities for her other "normal" children. It is a weakness of this study that we lack a comparison group - parents of children who do not have DS. Certainly it would be interesting to know if the processes we have identified in this sample can be seen in the lives and stories of individuals who have not been through an exceptional experience. Future work might examine how individuals construct happy endings and meaningful stories in contexts that make somewhat less grand demands on the storyteller. Such an investigation would allow for an examination of the process of accommodation of the less dramatic life events that may characterize most lives.

\section{REFERENCES}

Adams, G. R., \& Shea, J. (1979). The relationship between identity status, locus of control, and ego development. Journal of Youth and Adolescence, 8, 81-89.

Affleck, G., \& Tennen, H. (1996). Construing benefits from adversity: Adaptational significance and dispositional underpinnings. Journal of Personality: Special Issue on Personality and Coping, 64, 899-922.

Aiken, L. S., \& West, S. G. (1993). Multiple regression: Testing and interpreting interactions, Newbury Park, CA: Sage. 
Antonovsky, A. (1988). Unraveling the mystery of health. San Francisco: Jossey-Bass.

Antonovsky, A. (1993). The structure and properties of the sense of coherence scale. Social Science and Medicine, 36, 725-733.

Baltes, P. B., \& Staudinger, U. M. (1993). Search for a psychology of wisdom. Current Directions in Psychological Science, 2, 75-80.

Baltes, P. B., Staudinger, U. M., Maercker, A., \& Smith, J. (1995). People nominated as wise: A comparative study of wisdom-related knowledge. Psychology and Aging, 10, 155166.

Becker, L. (1992). Good lives: Prolegomena. Social Philosophy and Policy, 9, 15-37.

Block, J. (1982). Assimilation, accommodation, and the dynamics of personality development. Child Development, 53, 281-295.

Bursik, K. (1991). Adaptation to divorce and ego development in adult women. Journal of Personality and Social Psychology, 60, 300-306.

Diener, E., Emmons, R. A., Larsen, R. J., \& Griffin. G. (1985). The Satisfaction with Life Scale. Journal of Personality Assessment, 49, 71-75.

Frankl, V. (1985). Man's search for meaning (Revised). New York: First Washington Square Press.

Helson, R. (1992). Women's difficult times and rewriting the life story. Psychology of Women Quarterly, 16, 331-347.

Helson, R., \& Roberts, B. W. (1994). Ego development and personality change in adulthood. Journal of Personality and Social Psychology, 66, 911-920.

Helson, R., \& Wink, P. (1987). Two conceptions of maturity examined in the findings of a longitudinal study. Journal of Personality and Social Psychology, 53, 531-541.

Hy, L. X., \& Loevinger, J. (1996). Measuring ego development (2nd ed). Mahwah, NJ: Erlbaum.

Janoff-Bulman, R. (1992). Shattered assumptions: Toward a new psychology of trauma. New York: Free Press.

Janoff-Bulman, R. (1998). From terror to appreciation: Confronting change after extreme misfortune. Psychological Inquiry, 9, 99-101.

Janoff-Bulman, R., \& Berg, M. (1998). Disillusionment and the creation of value: From traumatic losses to existential gains. In J. Harvey (Ed.), Perspectives on loss: A sourcebook (pp. 35-47). Philadelphia, PA: Brunner-Mazel.

Janoff-Bulman, R., \& McPherson,-Frantz, C. (1997). The impact of trauma on meaning: From meaningless world to meaningful life. In M. J. Power and C. R. Brewein (Eds.), The transformation of meaning in psychological therapies: Integrating theory and practice (pp. 91-106). Chicester, UK: Wiley and Sons.

Kegan, R. (1982). The evolving self: Problem and process in human development. Cambridge MA: Harvard Univ. Press.

King, L. A., \& Napa, C. K. (1998). What makes a good life? Journal of Personality and Social Psychology, 75, 156-165.

Kling, K. C., Ryff, C. D., \& Essex, M. J. (1997). Adaptive changes in the self-concept during a life transition. Personality and Social Psychology Bulletin, 23, 981-990.

Krantz, D. L. (1998). Taming chance: Social science and everyday narratives. Psychological Inquiry, 9, 87-94.

Loevinger, J. (1976). Ego development: Conception and theories. San Francisco, CA: JosseyBass. 
Loevinger, J., \& Wessler, R. (1970). Measuring ego development: Vol. 1. Construction and use of a sentence completion test. San Fransisco: Jossey-Bass.

McAdams, D. P. (1993). The stories we live by: personal myths and the making of the self. New York: Morrow.

McAdams, D. P. (1996). Narrating the self in adulthood. In J. E. Birren, G. M. Kenyon, J. Ruth, J. J. F. Schroots, \& T. Svensson, (Eds.), Aging and biography: Explorations in adult development (pp. 131-148). New York: Springer-Verlag.

McAdams, D. P., \& de St. Aubin, E. (1992). A theory of generativity and its assessment through self-report, behavioral acts, and narrative themes in autobiography. Journal of Personality and Social Psychology, 62, 1003-1015.

McAdams, D. P., de St. Aubin, E., \& Logan, R. L. (1993). Generativity among young, midlife, and older adults. Psychology and Aging, 8, 221-230.

McAdams, D. P., Ruetzel, K., \& Foley, J. M. (1986). Complexity and generativity at midlife: Relations among social motives, ego development, and adults' plans for the future. Journal of Personality and Social Psychology, 50, 800-807.

Myers, D. G., \& Diener, E. (1995). Who is happy? Psychological Science, 6, 10-19.

Park, C. L., Cohen, L. H., \& Murch, R. L. (1996). Assessment and prediction of stress-related growth. Journal of Personality, 64, 71-105.

Pennebaker, J. W. (1989). Confession, inhibition and disease. In L. Berkowitz (Ed.), Advances in experimental social psychology (Vol. 22, pp. 211-244). New York: Springer-Verlag.

Redmore, C., \& Loevinger, J. (1979). Ego development in adolescence: Longitudinal studies. Journal of Youth and Adolescence, 8, 1-20.

Rosenberg, M. (1979). Conceiving the self. New York: Basic Books.

Ryff, C. D. (1989). Happiness is everything, or is it? Explorations on the meaning of psychological well-being. Journal of Personality and Social Psychology, 57, 1069-1081.

Ryff, C. D., \& Singer, B. (1998). The contours of positive mental health. Psychological Inquiry, 9, 1-28.

Scheier, M., \& Carver, C. S. (1985). Optimism, coping and health: Assessment and implications of generalized outcome expectancies. Health Psychology, 4, 219-247.

Taylor, S. E. (1983). Adjustment to threatening events: A theory of cognitive adaptation. American Psychologist, 38, 1161-1173.

Taylor, S. E. (1989). Positive illusions: creative self deception and the healthy mind. New York: Basic Books.

Taylor, S. E., \& Armor, D. A. (1996). Positive illusions and coping with adversity. Journal of Personality, 64(4), 873-898.

Taylor, S. E., \& Brown, J. D. (1988). Illusion and well-being: A social psychological perspective on mental health. Psychological Bulletin, 103(2), 193-210.

Taylor, S. E., Lichtman, R. R., \& Wood, J. V. (1984). Attributions, beliefs about control, and adjustment to breast cancer. Journal of Personality and Social Psychology, 46, 489-502.

Taylor, S. E., Wood, J. V., \& Lichtman, R. R. (1983). It could be worse: Selective evaluations as a response to victimization. Illusion and well-being: A social Psychological perspective on mental health. Journal of Social Issues, 39, 81-102.

Tennen, H., Affleck, G., \& Mendola, R. (1991a). Coping with smell and taste disorders. In T. Gechell, R. Doty, L. Bartoshuk, \& J. Snow (Eds.), Smell and taste in health and disease (pp. 787-801). New York: Raven Press.

Tennen, H., Affleck, G., \& Mendola, R. (1991b). Causal explanations for infertility: Their relation to control appraisals and psychological adjustment. In A. Stanton \& C. Dunkel 
Shetter (Eds.), Infertility: Perspectives from stress and coping research (pp. 109-132). New York: Plenum.

Thompson, S. C. (1991). The search for meaning in a stroke. Basic and Applied Social Psychology, 12, 81-96.

Vaillant, G. E., \& McCullough, L. (1987). The Washington University Sentence Completion Test measured with other measures of adult ego development. American Journal of Psychiatry, 144(9), 1189-1194.

Van Riper, M., Ryff, C., \& Pridham, K. (1992). Parental and family well-being in families of children with Down syndrome: A comparative study. Research in Nursing \& Health, 15(3) 227-235.

White, M. S. (1985). Ego development in adult women. Journal of Personality, 53, 561-574. 